\title{
Emission Performance of a Diesel Engine Fuelled with Petrol Diesel, Green Diesel, and Waste Cooking Oil Blends
}

\author{
O. Chiavola (iD) and E. Recco \\ Engineering Department, Roma Tre University, 00146 Rome, Italy \\ Correspondence should be addressed to O. Chiavola; ornella.chiavola@uniroma3.it
}

Received 31 January 2018; Revised 6 April 2018; Accepted 16 April 2018; Published 9 May 2018

Academic Editor: Constantine D. Rakopoulos

Copyright ( 2018 O. Chiavola and E. Recco. This is an open access article distributed under the Creative Commons Attribution License, which permits unrestricted use, distribution, and reproduction in any medium, provided the original work is properly cited.

\begin{abstract}
The purpose of this paper is to conduct an experimental research on the impact of mixing ratio of biodiesel from waste cooking oil and an innovative diesel fuel (in which a renewable component is contained) on the emissions of an up-to-date light and compact small engine that has a leading role in city cars and urban vehicles. Two blends' mixing ratios ( $20 \%$ and $40 \%$ by volume) were tested and the results were compared to those obtained when the engine was operated with low sulfur diesel (ULSD) and ULSD blended with $15 \%$ by volume of renewable diesel. The results indicate that diesel+ enhances $\mathrm{CO}$ and $\mathrm{HC}$ emissions in the exhaust as regards ULSD. Blending diesel+ with WCO causes a further reduction for most of the engine operative field. Concerning particulate emission, accumulation mode dominates for all fuels. Diesel+ is always characterized by lower mean diameters as regards ULSD. The addition of WCO further reduces the court mean diameter. Particle number concentration obtained by fuelling the engine with $\mathrm{B} 40$ is the lowest as regards all the other tested fuels. Concerning $\mathrm{NO}_{x}$, a moderate increase of the emission was observed when fuelling the engine with diesel+, net or in blends.
\end{abstract}

\section{Introduction}

Current and future legislation aimed at ensuring environmental sustainability together with economical and social concerns have led researchers to focus their activity on various alternatives to fossil fuels. Several attempts have been made for the substitution of petroleum fuels with other fuels. Biodiesel and green diesel are the most common diesel substitutes to be used either net or in mixtures with petroleum fuel in diesel engines.

Biofuels from crude vegetable oils, waste oils, and animal fats have been proposed and have demonstrated being able to substitute petroleum diesel, gaining support worldwide. These raw materials have to be transformed to be compatible with internal combustion engines. Numerous studies have been performed to analyse in detail the effects of fuel blends on the performance and emissions of diesel engines. Literature shows that feedstock type, chemical composition, and physical properties have a great influence on injection process, fuel ignition, combustion development, and exhaust gas composition. Moreover, the results are significantly affected by the blends ratios, specific engine configuration, and testing [1-3]. In general, a decrease of particulate emission, hydrocarbons, and carbon monoxide is observed with increasing of biodiesel content in the blends; biodiesel leads to increased nitrogen oxides $\left(\mathrm{NO}_{x}\right)$ compared to petroleum diesel $[4,5]$. Among all suitable biodiesel fuels, waste cooking oil (WCO) is considered a promising option and has demonstrated its suitability to be used as biofuel in diesel engines $[6,7]$. It offers advantages when used as a fuel source: WCO is 2-3 times less expensive than virgin vegetable oils [8]; the conversion of WCO into fuel also eliminates the environmental drawback caused by its disposal.

Green diesel, also called "second-generation diesel" and "renewable diesel," refers to petroleum-like fuels, derived from biological sources, that are chemically distinct from biodiesel. Green diesel is produced through an hydrogenation reaction in which feedstock reacts with hydrogen. A liquid hydrocarbon fuel is thus obtained that has the advantage of being fully compatible with petroleum diesel [9]. Literature shows that green diesel used in blends with petrol diesel in a diesel engine reduces emissions of unburned hydrocarbons 
TABLE 1: Engine specifications.

\begin{tabular}{lc}
\hline & LWD 442CRS \\
\hline Engine type & Common-rail, naturally aspirated, water-cooled \\
Cylinders & 2 \\
Displacement & $440 \mathrm{~cm}^{3}$ \\
Bore & $68 \mathrm{~mm}$ \\
Stroke & $60.6 \mathrm{~mm}$ \\
Compression ratio & $20: 1$ \\
Maximum power & $6.7 \mathrm{~kW} @ 3600 \mathrm{rpm}$ \\
Maximum torque & $20 \mathrm{Nm} @ 2400 \mathrm{rpm}$ \\
\hline
\end{tabular}

and carbon monoxide [5]. The main disadvantage of green diesel is that the high concentration of n-paraffins in the final fuel downgrades the cold properties of the fuel [10].

Although literature highlights considerable research activity on performance and emissions of many types of engines fuelled with biodiesel from different feedstock, most of the results have been obtained with engine designed for agricultural purpose, tested in specific values of engine speed and load conditions. Since experimentation proved that the specific engine and testing are responsible for some contradictory conclusions, the need of further investigation arises. Furthermore, there is a lack of knowledge about the effect of biodiesel content in blends of an innovative diesel fuel that already contains a fraction of renewable diesel. In addition, most of researches report data about particulate matter in terms of mass concentration and no information is provided in terms of size and number distribution.

The purpose of this work is to investigate the effect of the content of biodiesel from WCO in blends of petrol diesel and renewable diesel on the emission characteristics of an unmodified diesel engine.

An experimentation was performed on a small displacement, common-rail diesel engine, and a light and compact engine that has a leading role in city cars and urban vehicles. The urban congestion and the antipollution regulations on vehicles make this kind of engine very attractive in the future, especially if it is fuelled with biodiesel blends for their potential of reducing the pollutant emission in urban areas.

Two percentages of biodiesel content in the blend were analysed. Results in terms of gaseous emissions and particulate matter (size and number distribution) were compared to those obtained when the engine was operated with ultralow sulfur diesel (ULSD) and diesel+ (ULSD blended with $15 \%$ by volume of renewable diesel).

\section{Materials and Methods}

2.1. Engine and Experimental Setup. The experimentation was carried out on a two-cylinder, water-cooled, commonrail diesel engine, LWD 442CRS, manufactured by KOHLER. Its main technical specifications are listed in Table 1. It is a light and compact engine that has a leading role in microcars in urban areas.

The engine was installed in the test bed of the Engineering Department at "Roma Tre" University. It was connected to

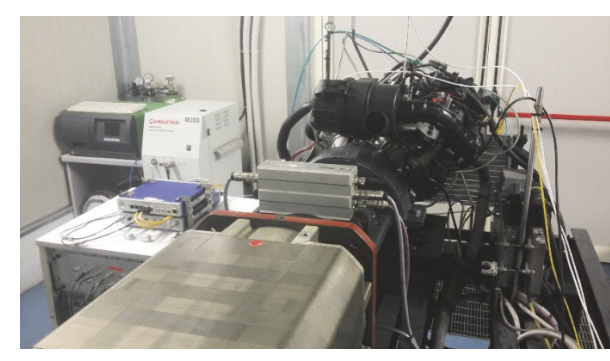

FIGURE 1: Experimental setup.

an asynchronous motor (Siemens 1PH7, nominal torque 360 $\mathrm{Nm}$, power $70 \mathrm{~kW}$ ) and was instrumented in order to fully characterize the engine operative conditions (Figure 1 shows the complete engine setup).

Torque measurement was carried out by means of HBM T12 (it is a strain gauge transducer with an optical encoder). The engine speed was measured by using an angular sensor (AVL 364C) with 2880 pulses/revolution.

AVL Fuel Balance 733 was used for fuel consumption measurement.

The in-cylinder pressure was measured with a piezoelectric pressure probe AVL GU13P that was installed in the preheating plug. Pressure transducers were installed along the intake and the exhaust systems for instantaneous pressure measurements.

The engine exhaust emissions $\left(\mathrm{CO}, \mathrm{CO}_{2}, \mathrm{HC}, \mathrm{O}_{2}\right.$, and $\mathrm{NO}_{x}$ expressed as $\mathrm{NO}$ equivalent) were measured with Bosch BEA352.

Particulate matter size was measured through Cambustion DMS500. This device uses a classifier column to compute the particle size distribution in the range $5 \mathrm{~nm}-1 \mu \mathrm{m}$, with a size resolution of 16 channels per decade. Exhaust gas passes first through a cyclone separator in order to remove particles above the measurement range $(1 \mu \mathrm{m})$. The sampling system consists of two dilution stages and a sampling line (a heated pipe $5 \mathrm{~m}$ long that connects the sampling point to the dilution stages and to the instrument). Primary and second dilution rates were set to $5: 1$ and $400: 1$, respectively. The diluted gas sample passes through a corona charger and then into the classifier column. The charged particles flow within a particlefree sheath flow and are deflected towards grounded electrometer rings by their repulsion from a central high voltage rod. Their landing position is a function of their charge and their aerodynamic drag. The particles yield their charge to the electrometer amplifiers and the resulting currents are translated by the user-interface into particle number and size data.

Software developed by the authors in LabVIEW10 environment was used to manage the tests conditions and to perform data monitoring/acquisition [11].

2.2. Fuels and Tests. Some preliminary investigations were performed with the objective of selecting the maximum percentage of WCO in diesel+ that was able to be tested without the need of modification to the engine hardware. It was established that $40 \%$ of WCO in the blend is the highest 
TABLE 2: Composition of biodiesel from WCO.

\begin{tabular}{lc}
\hline Mass fraction & Biodiesel \\
\hline Carbon & 0.812 \\
Hydrogen & 0.065 \\
Oxygen & 0.117 \\
Sulfur & 0.006 \\
\hline
\end{tabular}

quantity of biodiesel that can be tested, since higher percentage of biodiesel in the blend may not be compatible with certain metals causing corrosion, and elastomers and seals may swell or harden, according to previous experimental tests [12]. The experimentation was thus performed with a biodiesel from WCO percentage lower than $40 \%$ by volume; this allowed the investigated blends to be ready for use in actual engine. Four fuels were used:

(i) ULSD

(ii) diesel+: standard ultralow sulfur diesel fuel with $15 \%$ by volume of renewable diesel [13]

(iii) B20: diesel+ $80 \%$, biodiesel from WCO $20 \%$ by volume

(iv) B40: diesel+ $60 \%$, biodiesel from $\mathrm{WCO} 40 \%$ by volume.

Green diesel was obtained starting from palm oil, via the Ecofining ${ }^{\mathrm{TM}}$ Process [14]. It is a versatile solution for producing green diesel from a range of sustainable feedstock types. During the process, decarboxylation, hydrodeoxygenation, and hydroisomerization reactions are used to produce a high quality diesel fuel from biooils plus hydrogen at mild conditions. The obtained fuel does not contain oxygen and unlike traditional biodiesel it is totally hydrocarbon.

Diesel+ was tested by itself and then it was used as base fuel to prepare two blends, by mixing it with biodiesel produced from waste oil. WCO is a second-generation biodiesel that was obtained starting from a mixture of waste cooking oils. Due to its poor quality, it required some treatments in order to become similar to a product obtained from refined vegetable oils. A first-stage self-cleaning disk separator was used to remove $90 \%$ of the water containing the water-soluble matter and solids; a second-stage disk separator machine was used to remove the water leftover. Physical deacidification was also needed to remove organic free acidity due to the product deterioration as a consequence of the use in food cooking. The neutralized product was then converted via a transesterification process. The resulting raw biodiesel, coming from poor raw material, was distilled in order to comply with the reference specifications of biodiesel (EN 14214). Details of the procedure may be found in [12]. Table 2 reports the composition of the obtained biodiesel.

The properties of biodiesel from WCO, green diesel, ULSD, and diesel+ are listed in Table 3.

Stationary tests were carried out in the complete engine operative field (from $2400 \mathrm{rpm}$ to $3600 \mathrm{rpm}$ ). Load condition was varied in the field $50-80 \%$ as regards the available torque at full load condition evaluated by using diesel fuel. The maximum value was established by testing the engine with

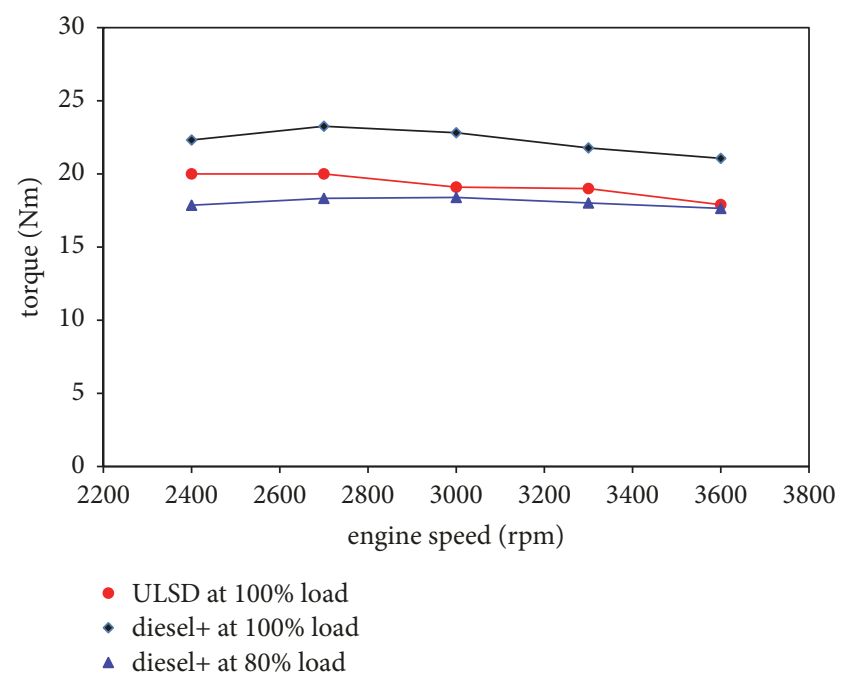

FIGURE 2: Engine torque variation with engine speed.

the different blends and by computing the load able to ensure the same value for all the tested fuels. The injection strategy and settings were not changed to account for the fuel properties.

Measurements were performed once oil and coolant temperatures reached final steady-state thermal regime. The sampling frequency was varied according to the engine speed in order to ensure a fixed angular resolution of the signals; all signals were averaged over 25 engine cycles.

During the experimentation, switching from one fuel to another was carried out by giving to the engine enough time to consume the remaining fuel in the supply system, before data acquisition started.

\section{Results and Discussion}

This section presents the performance and exhaust emission characteristics obtained in the complete operative field of the unmodified engine when it was fuelled with the fuel and blends previously mentioned. Figure 2 shows the variation of engine torque with engine speed. Three trends are plotted. Two of them were obtained with the engine at $100 \%$ condition with ULSD and diesel+ and they are shown to highlight the difference in engine available torque caused by the different fuel properties. The third one represents the partial load condition of $80 \%$ as regards the full throttle opening obtained with diesel+.

Each point of such a curve represents the operative condition imposed to the engine in the experimentation; this allowed testing the different fuels by imposing the same load value (the lower energy content of WCO as regards ULSD and diesel+ causes a reduction of available torque at full load condition). During tests, the same injection strategy was imposed on the engine: a two-shot injection pattern was implemented for each operating condition; timing and phasing of the shots were adjusted at each operating condition but did not change with the fuel type. A fixed quantity (equal to $1 \mathrm{~mm} 3 /$ stroke) was delivered during preinjection. During main injection, 
TABLE 3: ULSD, green diesel, and biodiesel from WCO and diesel+ properties.

\begin{tabular}{lcccc}
\hline Property & ULSD & Green diesel & Biodiesel from WCO & Diesel+ [15] \\
\hline Density $\left[\mathrm{kg} / \mathrm{m}^{3}\right.$ at $\left.15^{\circ} \mathrm{C}\right]$ & 830 & 780 & 877 & 840 \\
Lower heating value $[\mathrm{MJ} / \mathrm{kg}]$ & 43.1 & 44 & 37.1 & 43.2 \\
Cetane number & 52 & 80 & 56 & 55 \\
\hline
\end{tabular}

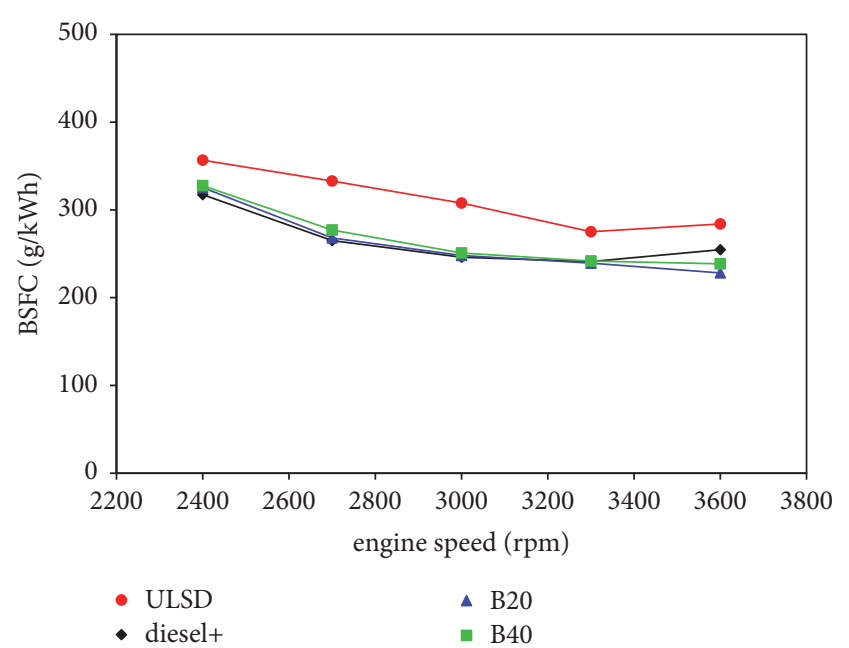

FIgURE 3: Brake thermal efficiency variation with engine speed at $80 \%$ load.

adjustment of fuel quantity allowed imposing the same torque value with all fuels.

Aimed at evaluating the fuel efficiency, the brake specific fuel consumption (BSFC) was computed and in Figure 3 the data obtained for ULSD, diesel+, B20, and B40 are shown. The trends indicate that diesel+, used net or in blends with WCO, has lower BSFC as regards ULSD. The results highlight a modest increase of fuel consumption with the WCO content in the blend, which is ascribed to the reduction of the energy content in biodiesel as compared to ULSD and green diesel and to some improvements in the combustion process due to the oxygenate nature of WCO. This is in agreement with a previous experimentation of WCO in blends with ULSD [12] and with results from literature related to the investigation of biodiesel from many feedstock types $[16,17]$.

Figure 4 shows the variation of brake thermal efficiency (BTE) with engine speed at a constant value of load condition. It was computed by dividing the power delivered to the crankshaft by the power provided by the fuel. The data show the lower efficiency characterizing ULSD as regards diesel+. The presence of biodiesel does not modify in substance the diesel+ behaviour, since only a small increase of BTE can be observed with the WCO content in the blend.

Figure 5 shows the in-cylinder pressure obtained during a test at $3000 \mathrm{rpm}$ and $80 \%$ of load. Injection timings were maintained unchanged for all fuels: preinjection of $1 \mathrm{~mm}^{3}$ starts at $18 \mathrm{cad}$ BTDC. Main injection starts at 8 cad BTDC. The comparison between ULSD and diesel+ (pure or blended) curves highlights the cetane number effect on the pressure development. The higher $\mathrm{CN}$ of diesel+ causes a shorter

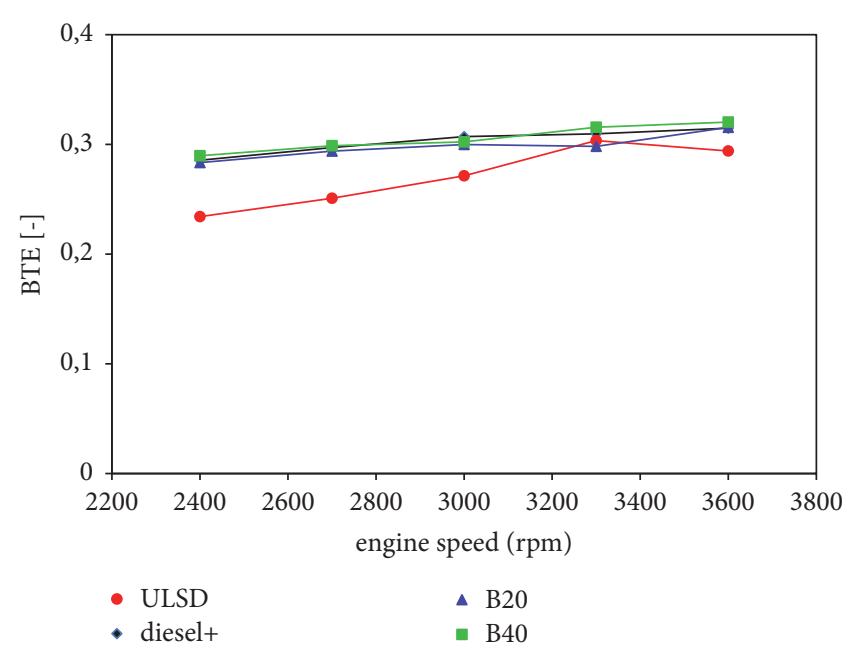

FIGURE 4: Brake specific fuel consumption variation with engine speed at $80 \%$ load.

ignition delay; the ignition occurs in a very brief interval of time after injection begins. The higher density of diesel+ as regards ULSD causes a longer spray penetration [18]; the higher viscosity of WCO as regards ULSD provides high penetration of the fuel jet and larger droplet diameters [19]. As the WCO content in the blend rises, the narrow increase of $\mathrm{CN}$ is responsible for a shorter ignition delay. The maximum pressure was observed for diesel+ and its blends; the cylinder pressure peaks were obtained nearly at the same crank angle position.

In Figures 6-13, the exhaust emissions variation with engine speed is shown.

Figure 6 presents carbon monoxide data. $\mathrm{CO}$ is the primary intermediate product during the combustion process. Low oxygen concentration, low reaction temperature, and short reaction time are responsible for CO formation [20]. All trends highlight that when the engine runs at lower speed values, lower in-cylinder temperature causes a detrimental effect on CO emission; at higher engine speed, there may not be enough time for complete combustion and hence more $\mathrm{CO}$ in the exhaust.

CO emission of diesel+ is lower as regards ULSD. Biodiesel performs better than renewable diesel in terms of $\mathrm{CO}$ exhaust emission, in accordance with [5]; it may be attributed to the oxygen content of the biodiesel that enhances the mixing process in the combustion chamber, thus lowering $\mathrm{CO}$ emission. The addition of $20 \%$ of WCO in diesel+ causes a remarkable reduction of $\mathrm{CO}$ as regards diesel+. A further increase of WCO content in the blend does not provide a significant improvement of the emission compared to diesel+. 


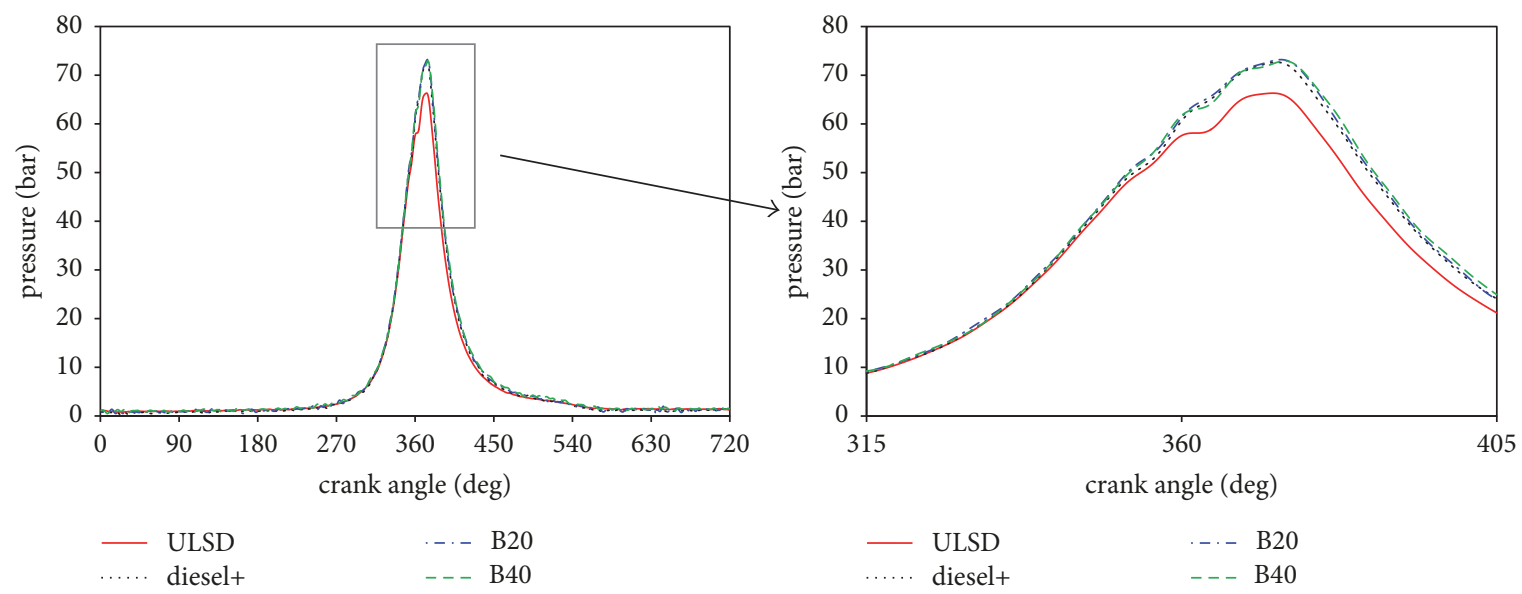

FIGURE 5: Variation of in-cylinder pressure with engine speed at $3000 \mathrm{rpm}$ and $80 \%$ load (18 Nm).

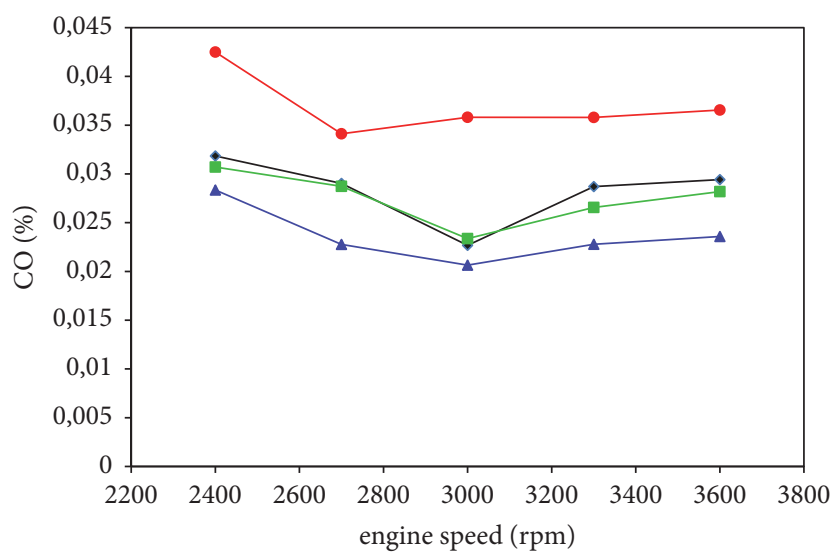

- ULSD

- diesel+

$\Delta \mathrm{B} 20$

- B40

FIGURE 6: CO emission variation with engine speed at $80 \%$ load.

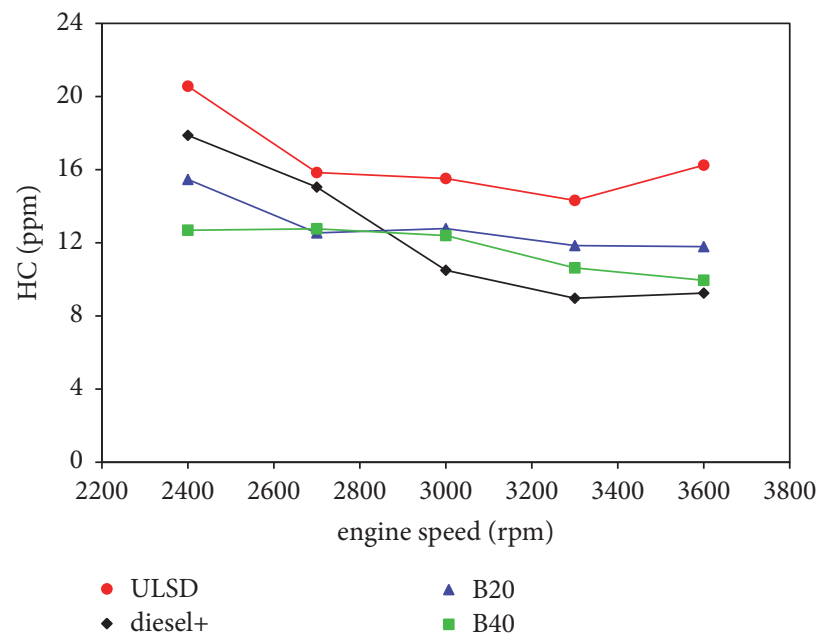

Figure 7: HC emission variation with engine speed at $80 \%$ load.

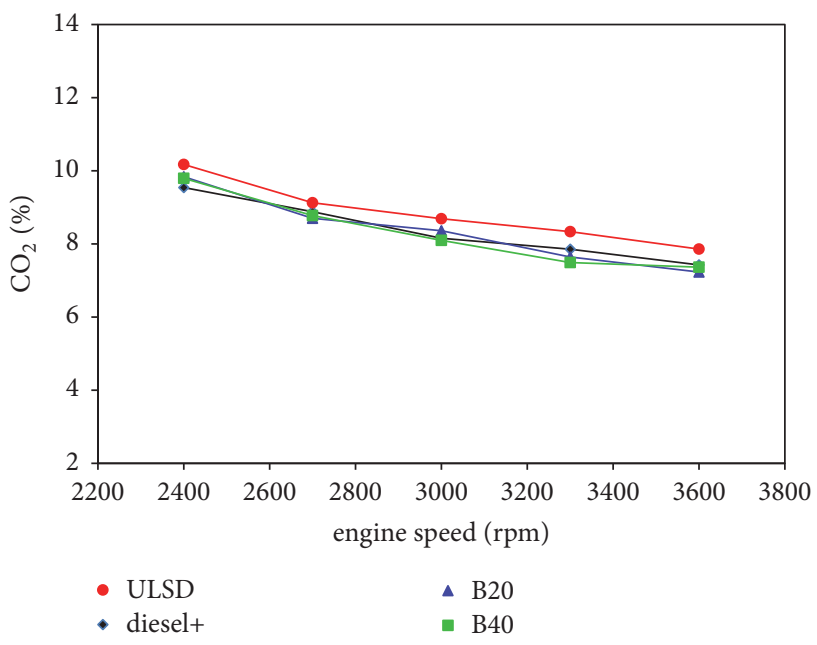

FIGURE 8: $\mathrm{CO}_{2}$ variation with engine speed at $80 \%$ load.

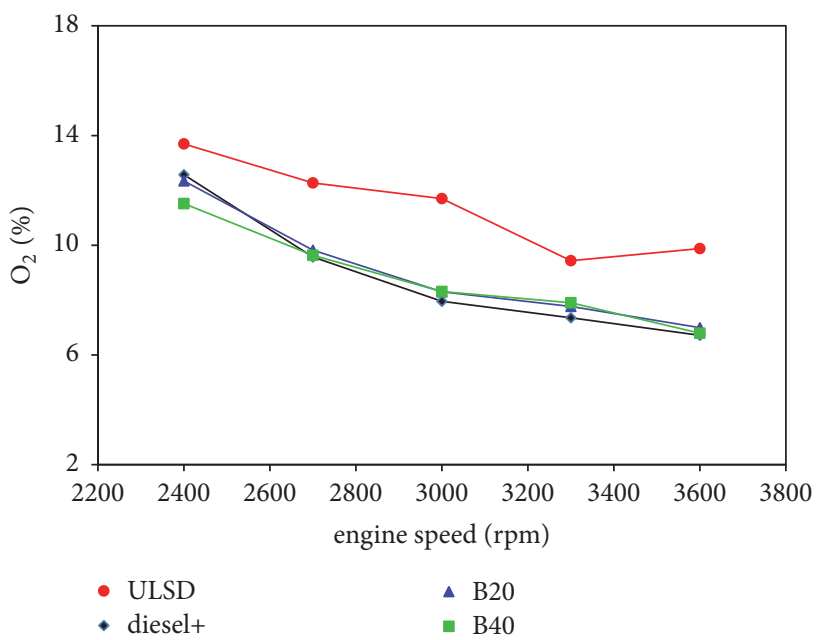

Figure 9: $\mathrm{O}_{2}$ variation with engine speed at $80 \%$ load. 


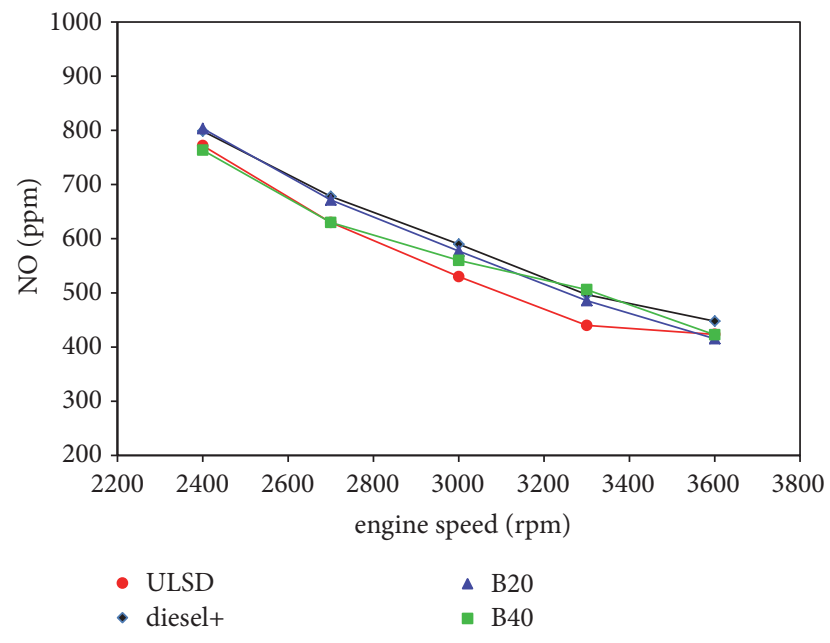

FIGURE 10: NO variation with engine speed at $80 \%$ load.

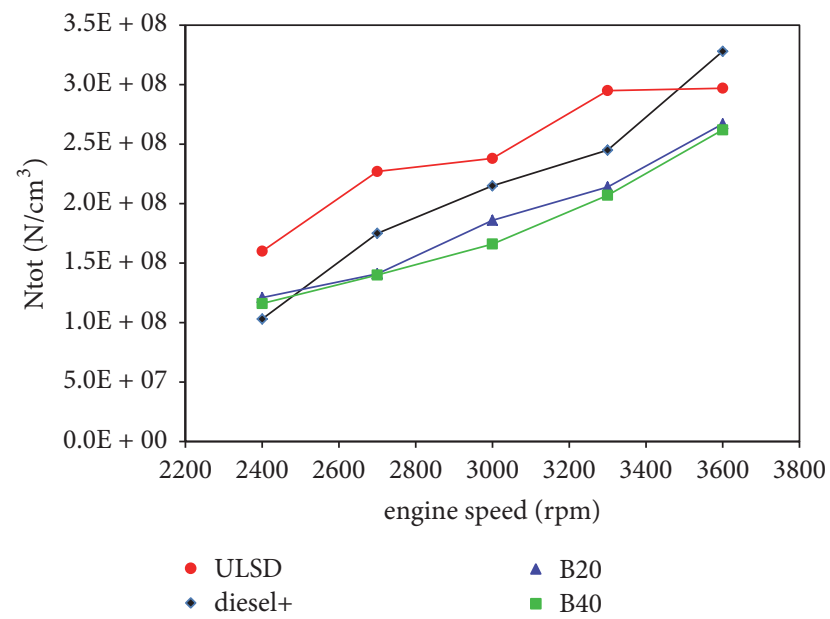

FIGURE 11: Variation of particle number concentration with engine speed at $80 \%$ load.

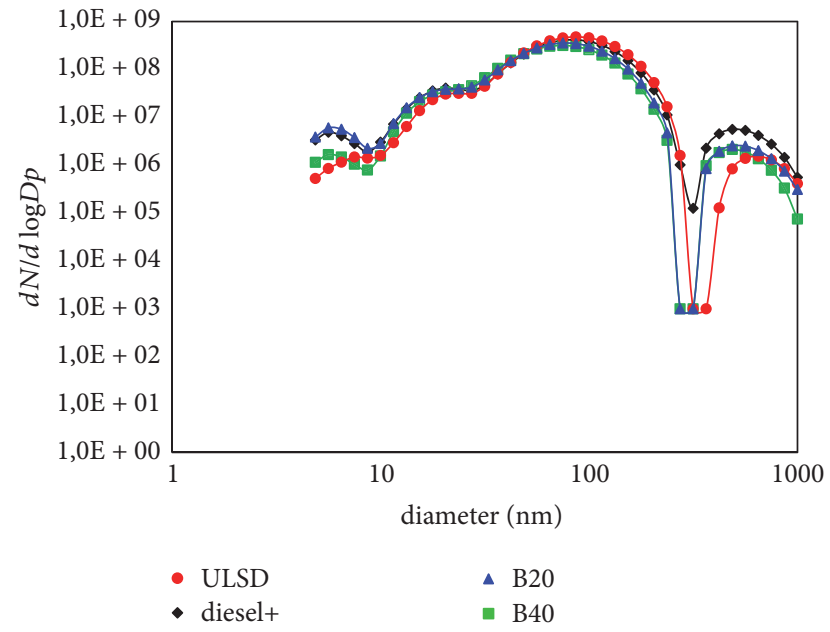

FIGURE 12: Variation of particle diameter with engine speed at $3000 \mathrm{rpm}$ and $80 \%$ load $(18 \mathrm{Nm})$.

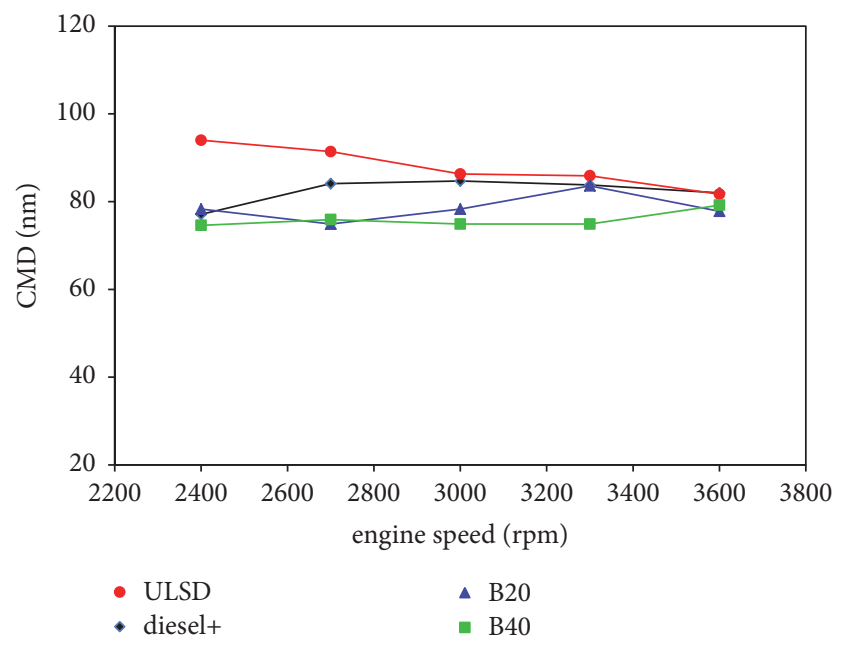

FIGURE 13: Variation of accumulation mean diameter with engine speed at $80 \%$ load.

Hydrocarbon emission versus engine speed is shown in Figure 7. HC is mainly the result of flame extinction in the cold region of the chamber; it is also generated in locally lean and locally rich regions. Its formation is related to the fuel volatility, viscosity, and cetane number $(\mathrm{CN})[21,22]$, too. The trends highlight that diesel+ net or in blends with WCO has a positive effect on this emission. The amount of $\mathrm{HC}$ reduction is related to the blend ratio, besides the engine speed value. In accordance with [23], B40 behaves always better than B20. B20 has HC emission lower than diesel+ at lower engine speed, while at higher values of engine speed, diesel+ has the lowest $\mathrm{HC}$ emission.

Figure 8 presents the variation of carbon dioxide with the engine speed at $80 \%$ of load. The data show that the fuels behave almost in the same way. Diesel+, net or in blends, has a limited reduction as compared with ULSD. Literature reports that biodiesel has higher $\mathrm{CO}_{2}$ emissions compared to diesel fuel, due to the higher density with increases in the overall mass of delivered fuel; more complete combustion with biodiesel may have also a contribution [24].

Oxygen concentration in the exhaust is shown in Figure 9. diesel+ and its blends with WCO are characterized by a reduction of $\mathrm{O}_{2}$ as regards ULSD. The quantity of biodiesel does not significantly affect the percentage concentration.

Figure 10 shows the nitrogen oxides emission, expressed as $\mathrm{NO}$ equivalent. The formation of thermal $\mathrm{NO}_{x}$ (dominant in diesel engines) is strongly dependent on the local oxygen concentration, maximum temperature, and residence time [25]. In agreement with results from literature, no matter what the fuel is, NO is reduced as engine speed increases [26]. Such a behaviour may be attributed to the increase of gas flow motion in the cylinder as the engine speed rises, which causes a faster mixing between fuel and air and a shorter ignition delay and thus a reduction of the maximum temperature in the chamber. This effect, combined with the reduction of residence time as the engine speed increases leads to $\mathrm{NO}_{x}$ decrease with engine speed rise. 
Differences among the traces are due to the properties of the fuel; cetane number affects the ignition delay and accordingly the combustion phasing. Since diesel+ has higher $\mathrm{CN}$ as regards ULSD, it is characterized by a shorter ignition delay; thus ignition occurs in a very brief interval of time after the injection begins. The fuel amount in premixed combustion phase decreases, resulting in lower maximum incylinder pressure as regards ULSD, thus affecting the $\mathrm{NO}_{x}$ formation [20]. The higher heating value of diesel+ as regards ULSD has an opposite effect on $\mathrm{NO}_{x}$ emission. The points in the plot are the results of the combined effect of these parameters, taking into account the fact that no modification of the injection settings was imposed on the engine. Biodiesel content in the blend does not remarkably affect $\mathrm{NO}_{x}$ in the exhaust: B20 data are very similar to those of diesel+, and B40 points have values between those related to ULSD and diesel+. The oxygen content in the fuel plays an important role in $\mathrm{NO}_{x}$ formation; it encourages complete combustion and higher combustion temperatures, thus resulting in increased thermal $\mathrm{NO}_{x}$ on the one hand. In order to guarantee the same available load, the injected fuel is increased with biodiesel content in the blend, due to the lower energy content of biodiesel; temperature is maintained more or less constant, while the oxygen content in the exhaust is affected together with $\mathrm{NO}_{x}$ production, on the other hand. Differences in chemical and physical properties of biodiesel have also a great influence on $\mathrm{NO}_{x}$ formation $[1,27]$.

Results related to particulate matter are shown in Figures 11,12 , and 13. All trends exhibit an increase of the number of particles as the engine speed rises, in accordance with data from literature. This behaviour is ascribed to a balance between the reduced time available for reactions, which results in a more incomplete combustion and then in a higher particulate concentration [28], and the enhancement of turbulence effects with the engine speed increase promotes the completeness of combustion process [4].

The higher CN of diesel+ and its blends as regards ULSD shortens the ignition delay and elongates the duration of mixed-controlled combustion, thus reducing the particulate in the exhaust. In diesel+ blends, the reduction of total number of emitted particles with the increase of WCO fraction is caused by concomitant aspects: the oxygen content in the fuel reduces locally overrich regions and limits the primary smoke formation [28]; the higher viscosity and density of biodiesel deteriorate the fuel atomization [29].

Aimed at investigating how the fuel type affects the number and size distribution of particle emissions, the soot size spectral density was analysed. Figure 12 shows the soot particle diameters and their number distribution obtained during experimental tests at $3000 \mathrm{rpm}$ and $80 \%$ of load. The particle number concentration is expressed as size spectral density, $d N / d \log D_{p} / c c$.

The traces highlight the prevalence of accumulation mode with regard to nucleation one for all tested fuels. For what concerns the highest diameters the instrument is able to detect, abrupt decreasing trends in the range of $1 \mu \mathrm{m}$ can be observed, especially for diesel+ and its blends. The employment of biodiesel allows obtaining a reduction of particles in this range that can be explained by considering the oxygen content of WCO, which favours the completeness of the combustion process, thus promoting the oxidation of the already formed soot and inhibiting its growth.

ULSD emission is characterized by a lower number of smaller sizes particles (under $50 \mathrm{~nm}$ ); as soon as the diameters increases, ULSD shows an increase of the number of particles compared with the other fuels.

The employment of diesel+ is responsible for an increase of the number of nanoparticles $\left(D_{p}<50 \mathrm{~nm}\right)$. WCO content in the blend with diesel+ affects such a feature: the increase of biodiesel percentage causes a reduction of ultrafine particles, which have concentrations always higher than ULSD. This is in agreement with literature data, where studies report that the employment of biodiesel blends produces an increased number of nanoparticles and a reduced number of ultrafine $\left(D_{p}<100 \mathrm{~nm}\right)$ in comparison with ULSD $[22,30]$.

Figure 13 shows the effect of engine speed on the mean diameter of accumulation mode (in all operative conditions a bimodal distribution of particle size was observed, in which accumulation mode dominates).

Diesel+ is always characterized by lower diameters as regards ULSD. The addition of biodiesel in diesel+ further reduces the diameters: the plot highlights that B40 has smaller mean diameters than B20. This is in agreement with a previous experimentation [31] and with literature. Such a behaviour is ascribed to the oxygen content of biodiesel that favours the combustion completeness in the region with fuel-rich diffusive combustion and the oxidation of soot particles and is unfavourable to their growth $[22,29]$.

\section{Conclusions}

An experimental investigation was performed to analyse the environmental impacts of alternative fuels, obtained by blending biodiesel from WCO with diesel fuel in which renewable diesel is contained.

Testing was performed on a light and compact up-to-date engine that equips city cars and urban vehicles. The impact of two blend ratios on emission performance was analysed in the complete engine operative field with no modification of the system hardware; the injection strategy and settings were not changed to account for the fuel properties.

The employment of diesel+ enhances $\mathrm{CO}$ and $\mathrm{HC}$ emissions in the exhaust as regards ULSD. Blending diesel+ with WCO allows obtaining a further reduction of them in almost all engine speed values. The same behaviour was observed for particulate matter emission: the particle number concentration obtained by fuelling the engine with B40 is the lowest as regards all the other tested fuels. Accumulation mode dominates for all fuels in the complete engine operative field. Diesel+ is always characterized by lower diameters as regards ULSD. The addition of WCO further reduces the court mean diameter. Concerning $\mathrm{NO}_{x}$, fuelling the engine with diesel+, net or in blends, causes a moderate increase of the emission.

\section{Nomenclature}

B20: Diesel+ $80 \%$, biodiesel from WCO $20 \%$ by volume B40: Diesel $+60 \%$, biodiesel from WCO $40 \%$ by volume 
BSFC: Brake specific fuel consumption

BTE: Brake thermal efficiency

CMD: Court mean diameter

$\mathrm{CN}$ : Cetane number

ULSD: Ultralow sulfur diesel

WCO: Waste cooking oil.

\section{Data Availability}

The data used to support the findings of this study are available from the corresponding author upon request.

\section{Conflicts of Interest}

The authors declare that there are no conflicts of interest regarding the publication of this paper.

\section{References}

[1] H. Song, B. T. Tompkins, J. A. Bittle, and T. J. Jacobs, "Comparisons of $\mathrm{NO}$ emissions and soot concentrations from biodieselfuelled diesel engine," Fuel, vol. 96, pp. 446-453, 2012.

[2] J. Sun, J. A. Caton, and T. J. Jacobs, "Oxides of nitrogen emissions from biodiesel-fuelled diesel engines," Progress in Energy and Combustion Science, vol. 36, no. 6, pp. 677-695, 2010.

[3] H. An, W. M. Yang, S. K. Chou, and K. J. Chua, "Combustion and emissions characteristics of diesel engine fueled by biodiesel at partial load conditions," Applied Energy, vol. 99, pp. 363-371, 2012.

[4] J. Xue, T. E. Grift, and A. C. Hansen, "Effect of biodiesel on engine performances and emissions," Renewable \& Sustainable Energy Reviews, vol. 15, no. 2, pp. 1098-1116, 2011.

[5] G. Knothe, "Biodiesel and renewable diesel: a comparison," Progress in Energy and Combustion Science, vol. 36, no. 3, pp. 364373, 2010.

[6] A. Demirbas, "Progress and recent trends in biodiesel fuels," Energy Conversion and Management, vol. 50, no. 1, pp. 14-34, 2009.

[7] Ö. Can, "Combustion characteristics, performance and exhaust emissions of a diesel engine fueled with a waste cooking oil biodiesel mixture," Energy Conversion and Management, vol. 87, pp. 676-686, 2014.

[8] A. N. Phan and T. M. Phan, "Biodiesel production from waste cooking oils," Fuel, vol. 87, no. 17-18, pp. 3490-3496, 2008.

[9] A. Vonortas and N. Papayannakos, "Comparative analysis of biodiesel versus green diesel," Wiley Interdisciplinary Reviews: Energy and Environment, vol. 3, no. 1, pp. 3-23, 2014.

[10] P. Šimáček, D. Kubička, G. Šebor, and M. Pospíšil, "Fuel properties of hydroprocessed rapeseed oil," Fuel, vol. 89, no. 3, pp. 611-615, 2010.

[11] G. Chiatti, O. Chiavola, F. Palmieri, and A. Piolo, "Diagnostic methodology for internal combustion diesel engines via noise radiation," Energy Conversion and Management, vol. 89, pp. 3442, 2015.

[12] G. Chiatti, O. Chiavola, F. Palmieri, and S. Albertini, "Combustion and emissions characterization of biodiesel blends in a citycar engine," ENERGY \& FUELS, vol. 28, no. 8, pp. 5076-5085, 2014.

[13] T. Kalnes, T. Marker, and D. R. Shonnard, "Green Diesel: A Second Generation Biofuel," International Journal of Chemical Reactor Engineering, vol. 5, no. 1, 2007.
[14] F. Baldiraghi, M. Di Stanislao, G. Faraci et al., "Ecofining: New Process for Green Diesel Production from Vegetable Oil," in Sustainable Industrial Chemistry, Wiley-VCH Verlag GmbH \& Co. KGaA, Weinheim, Germany.

[15] https://oilproducts.eni.com/it_IT/prodotti/carburanti-e-combustibili/trazione/gasolio/eni-diesel.

[16] M. F. Othman, A. Adam, G. Najafi, and R. Mamat, "Green fuel as alternative fuel for diesel engine: A review," Renewable \& Sustainable Energy Reviews, vol. 80, pp. 694-709, 2017.

[17] J. K. Mwangi, W.-J. Lee, Y.-C. Chang, C.-Y. Chen, and L.-C. Wang, "An overview: energy saving and pollution reduction by using green fuel blends in diesel engines," Applied Energy, vol. 159, pp. 214-236, 2015.

[18] T. Bohl, G. Tian, A. Smallbone, and A. P. Roskilly, "Macroscopic spray characteristics of next-generation bio-derived diesel fuels in comparison to mineral diesel," Applied Energy, vol. 186, pp. 562-573, 2017.

[19] P.-C. Chen, W.-C. Wang, W. L. Roberts, and T. Fang, "Spray and atomization of diesel fuel and its alternatives from a single-hole injector using a common rail fuel injection system," Fuel, vol. 103, pp. 850-861, 2013.

[20] R. Li, Z. Wang, P. Ni, Y. Zhao, M. Li, and L. Li, "Effects of cetane number improvers on the performance of diesel engine fuelled with methanol/biodiesel blend," Fuel, vol. 128, pp. 180-187, 2014.

[21] R. Cataluña and R. Da Silva, "Effect of cetane number on specific fuel consumption and particulate matter and unburned hydrocarbon emissions from diesel engines," Journal of Combustion, vol. 2012, Article ID 738940, 2012.

[22] H. Kim and B. Choi, "The effect of biodiesel and bioethanol blended diesel fuel on nanoparticles and exhaust emissions from CRDI diesel engine," Journal of Renewable Energy, vol. 35, no. 1, pp. 157-163, 2010.

[23] F. Wu, J. Wang, W. Chen, and S. Shuai, "A study on emission performance of a diesel engine fueled with five typical methyl ester biodiesels," Atmospheric Environment, vol. 43, no. 7, pp. 1481-1485, 2009.

[24] J.-H. Ng, H. K. Ng, and S. Gan, "Engine-out characterisation using speed-load mapping and reduced test cycle for a lightduty diesel engine fuelled with biodiesel blends," Fuel, vol. 90, no. 8, pp. 2700-2709, 2011.

[25] L. Li, J. Wang, Z. Wang, and J. Xiao, "Combustion and emission characteristics of diesel engine fueled with diesel/biodiesel/pentanol fuel blends," Fuel, vol. 156, article no. 9201, pp. 211218, 2015.

[26] Ş. Altun, H. Bulut, and C. Öner, “The comparison of engine performance and exhaust emission characteristics of sesame oildiesel fuel mixture with diesel fuel in a direct injection diesel engine," Journal of Renewable Energy, vol. 33, no. 8, pp. 17911795, 2008.

[27] A. S. Cheng, A. Upatnieks, and C. J. Mueller, "Investigation of the impact of biodiesel fuelling on NOx emissions using an optical direct injection diesel engine," International Journal of Engine Research, vol. 7, no. 4, pp. 297-318, 2006.

[28] K. Yehliu, A. L. Boehman, and O. Armas, "Emissions from different alternative diesel fuels operating with single and split fuel injection," Fuel, vol. 89, no. 2, pp. 423-437, 2010.

[29] M. Lapuerta, O. Armas, and J. Rodriguez-Fernandez, "Effect of biodiesel fuels on diesel engine emissions," Progress in Energy and Combustion Science, vol. 34, no. 2, pp. 198-223, 2008. 
[30] A. Neer and U. O. Koylu, "Effect of operating conditions on the size, morphology, and concentration of submicrometer particulates emitted from a diesel engine," Combustion and Flame, vol. 146, no. 1-2, pp. 142-154, 2006.

[31] G. Chiatti, O. Chiavola, and F. Palmieri, "Impact of waste cooking oil in biodiesel blends on particle size distributions from a city-car engine," Journal of the Energy Institute, 2016. 


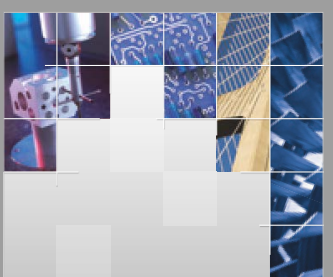

\section{Enfincering}
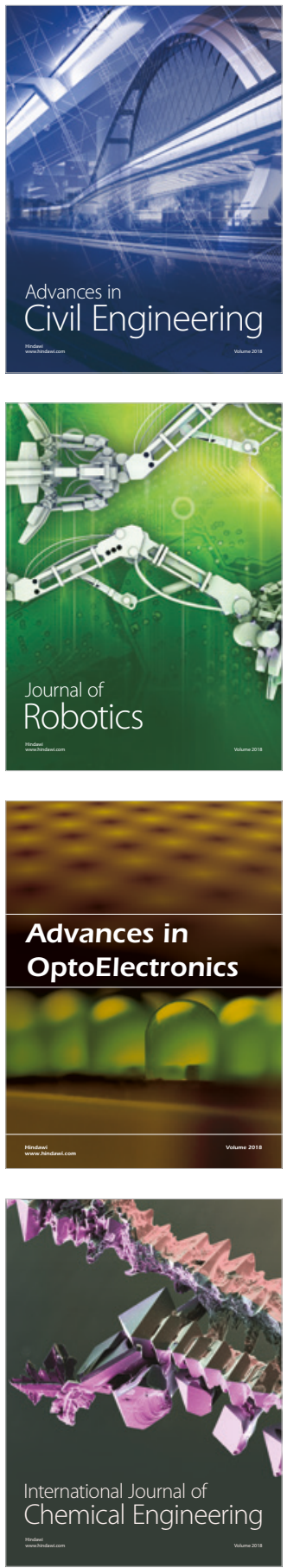

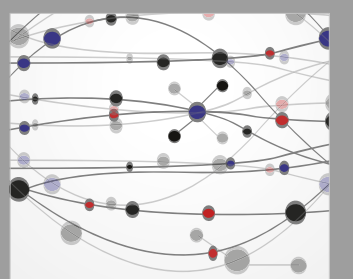

\section{Rotating \\ Machinery}

The Scientific World Journal

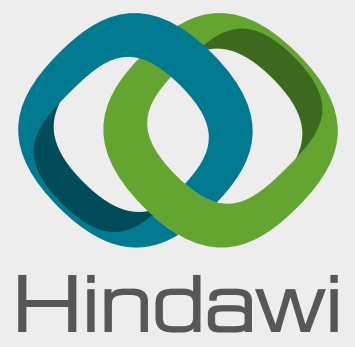

Submit your manuscripts at

www.hindawi.com
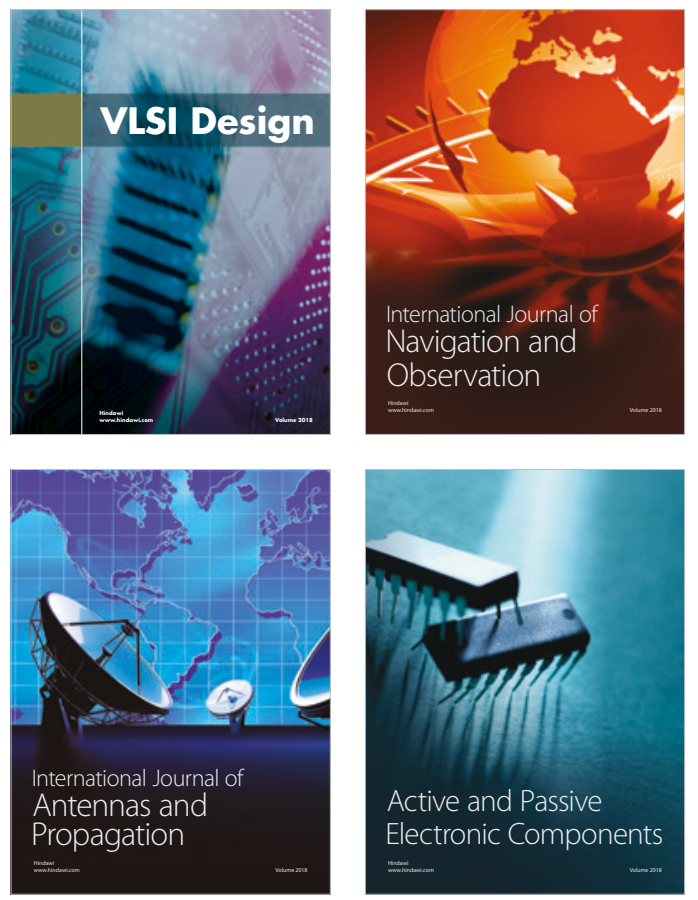
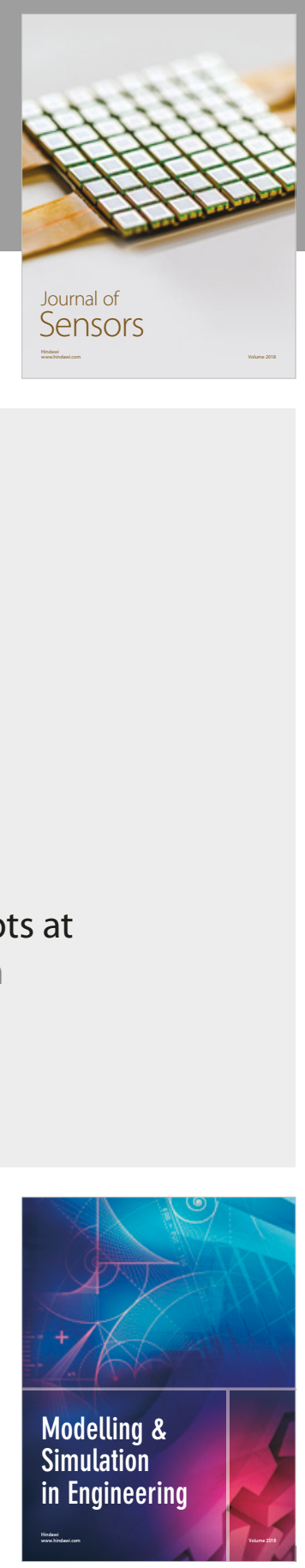

\section{Advances \\ Multimedia}
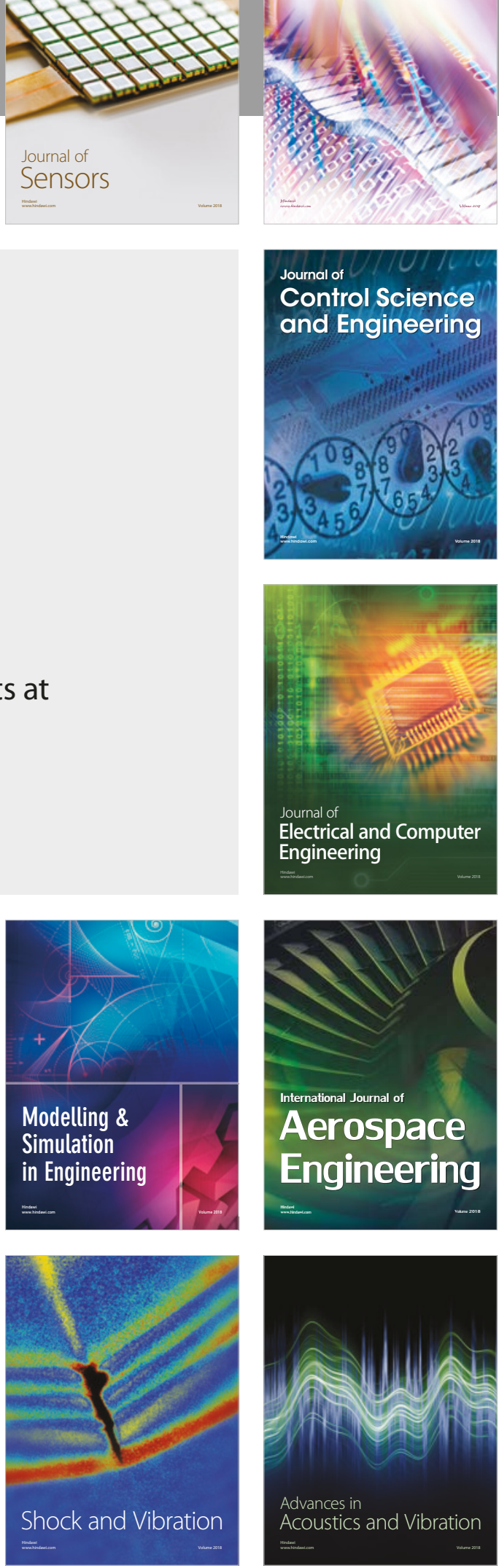